\title{
ANATOMIA COMPARADA DAS FOLHAS E EVOLUÇÃO DAS PODOCARPINEAE
}

\author{
Ph. Woltz ${ }^{1}$ \\ R. Gajardo ${ }^{2}$ \\ A.G. Ferreira ${ }^{3}$
}

\section{Recebido em 29.10.86. Aceito em 12.01.87.}

\begin{abstract}
Comparative foliar anatomy and evolution of the Podocarpineae.") The anatomy of 112 species out of the 184 at present recognized is compared. The evolutionary sequence proposed shows in several different "series" the passage by successive transformations from an ancestral type with short one-nerved leaves, well-developed sub-epidermis and many resin canals to those with long wide leaves, first one-nerved then several-nerved, with reduced sub-epidermis and few resin canals. An over-evolved condition sometimes produces at the end of a "serie" an apparent reversion to the ancestral type: leaves short or reduced to fleshy scales with late proliferation of canals separated in the mesophyll.

A striking correlation between foliar anatomy and geographic latitude suggests, as with vascular evolution in seedlings at the cotyledon stage (WOLTZ, 1986), a greater age for the most southern taxa.

Key-words: Podocarpineae, evơlution, anatomy comparative.

RÉSUMÉ - (Anatomie comparée des feuilles et evolution des Podocarpineae.) 184 espèces sont connues à ce jour, l'anatomie comparée des feuilles est réalisée sur 112 espèces disponibles. Un schéma évolutif est proposé: dans plusieurs phylums différents, évoluant de façon parallèle, un type ancestral à feuille courte uninerve, abondamment pourvu de sous-épiderme et de canaux résinifères passerait, par transformations successives à des types à feuilles longes, larges, uninerves, à sous-épiderme réduit et canaux résinifères peu nombreux. Parfois, en fin de phylum une surévolution amène à un faux retour ancestral: feuille courte ou en Écaille charnue et multiplication tardive de canaux séparés dans le mesophylle.

Comme dans le cas de l'évolution vasculaire de plantules cotylées (WOLTZ, 1986), un parallélisme remarquable existe entre lanatomie foliaire et la latitude géographique qui semble suggérer l'origine ancienne des taxons les plus austraux.
\end{abstract}

${ }^{1}$ Université Aix-Marseille 3, Morphogenèse végétale, U.A. CNRS 563, Centre de St-Jérôme, 13397 Marseille Cedex 13. France.

${ }^{2}$ Universidad de Chile. Departamento de Silvicultura, Facultad de Ciencias Agrarias y forestales, Casilla 9206, Santiago. Chile.

${ }^{3}$ Universidade Federal do Rio Grande do Sul, Departamento de Botânica. Av. Paulo Gama $\mathrm{n}^{\circ}$ 40 - Porto Alegre - RS. CEP 90049. BRASIL. 
RESUMEN - ("Anatomia comparada de las hojas y evolucion de las Podocarpineae.") En las Podocarpineae actualmente se conocen 184 especies, de las cuales 120 han sido estudiadas en la anatomía comparada de la hoja. Es propuesto el siguiente sistema evolutivo: en muchos phyla diferentes, evolucionando de manera paralela, un tipo ancestral de hoja corta uninervada, provisto abundantemente de sub-epidermis y de canales resiníferos, pasaría por transformaciones sucesivas a tipos con hojas largas, anchas, uninervadas a pluri-nervadas, con sub-epidermis reducida y canales resiníferos poco numerosos. A veces, en la culminación de phylum, una sobre-evolución conduce a un falso retorno ancestral: hoja corta o en escamas carnosas y multiplicación tardía de los canales separados en el mesófilo.

Como en el caso de la evolución vascular de las plantas cotiladas (WOLTZ, 1986), existe un paralelismo notable entre la anatomía foliar y la latitud geográfica, lo que parece sugerir el origen más antiguo de los taxa más australes.

\section{Introdução}

A anatomia foliar comparada das Podocarpineae, levou a exame 112 espécies sobre as 184 conhecidas atualmente. No passado, é provável que os autores, por laxismo, tenham exagerado a enumeração de espécies. Podemos considerar que certas espécies estão ligadas ao contexto geográfico: ilhas, picos de altas montanhas e são, de fato, afins. Assim, podemos restabelecer este número de 184 espécies para aproximadamente 150 .

Sabemos, a partir dos trabalhos de BUCHHOLZ e GRAY (1948), que o estudo anatômico das folhas é indispensável nas Podocarpineae. A maior parte das espécies são dióicas e os órgãos reprodutores $\sigma^{\top} \mathrm{e} O Q$ faltam freqüentemente em herbários ou são ainda desconhecidos. Certos trabalhos recentes de sistemática sobre as Podocarpineae são fundamentados somente em caracteres morfológicos, fazendo assim abstração completa de exames anatômicos: De LAUBENFELS (1969 etc...); QUINN (1982).

Percorrendo a detalhada bibliografia consagrada às Gimnospermas, é fácil se convencer que o gênero Podocarpus (s.l.) não foi largamente estudado e que nossos conhecimentos são muito fragmentados. $O$ histórico da questão mostra que a anatomia comparada das estruturas foliares é muito reduzida, se limitando freqüentemente ao estudo sistemático de algumas espécies de uma região ou de um país: BERTRAND (1874); MAHLERT (1885); Van TIEGHEM (1891); GRIFFIN (1907); BAKER e SMITH (1910); STILES (1912); ROBYNS (1935); GRIFFITH (1957); SCHOONRAAD (1974). Poucos documentos mais gerais existem: ORR (1944); BUCHHOLZ e GRAY (1948-1957); GAUSSEN (1973, 1974, 1976).

O objetivo deste trabalho, cobrindo em parte um estudo detalhado realizado por um de nós (WOLTZ, 1986), é de tentar desmembrar o sentido da evolução do grupo, indicado pelos caracteres anatômicos foliares, o que parece, até hoje, não ter sido ainda feito.

Nós seguiremos a classificação adotada por GAUSSEN (1973) para a subordem das Podocarpineae, que reagrupa 4 famílias: Saxegothaeaceae, Phyllocladaceae, Pherosphoeraceae e Podocarpaceae. As 3 primeiras são monogenéricas, as Podocarpaceae contam com mais de 170 espécies, com 8 gêneros: Acmopyle, Afrocarpus, Dacrycarpus, Dacrydium, Falcatifolium, Microcachrys, Podocarpus e Stachycarpus que traduzem uma evidente diversidade de formas e de adaptaçōes biológicas. 


\section{Morfologia foliar (Generalidades)}

As folhas de Podocarpineae são de tipos surpreendentemente variados: forma de agulhas, formas achatadas com limbo muito desenvolvido, forma de escamas lembrando as das Cupressáceas, sem esquecer o caso original apresentado por Phyllocladus: o tipo filoclado é um órgão "complexo" clorofilado, que pode resultar da estreita soldadura entre um ramo principal e um secundário desdobrado, associados a folhas aciculares.

A folhagem é persistente e se renova por um processo lento e contínuo: as folhas mais velhas caem isoladamente dos ramos ao fim de 8 à 10 anos em Podocarpus madagascariensis. A árvore não fica nunca desnuda, ela é sempre-verde (semper-virens).

A inserção das folhas no eixo é sempre espiralada, com filotaxia de $2 / 5$, as geratrizes não são ortósticas mas sim parásticas sinistras ou dextrógiras. Isto é claro em $P$. henkelii e $P$. neriifolia. KADAMBARI et al., (1968) acham um índice filotáxico de $3 / 8$ para $P$. macrophylla do Japão.

A folha tipo mais conhecida é a que lembra a folha de uma dicotiledônea, como Nerium oleander (espirradeira) - Apocynaceae. É uma folha longa, com limbo largo, uninérvea, sem pecíolo, com espessá cutícula no lado adaxial e estrutura hipostomática. O pecíolo existe, mas a folha é dita "decurrente": o pecíolo é soldado no caule por um certo comprimento e é marcado na última parte por um espessamento visível. As folhas sâo glabras, o ápice foliar apresenta freqüentemente um leve mucron.

De uma maneira geral as Podocarpales são esclerófitas, com exceção de Afrocarpus e as espécies da-seção Polypodiopsis. Assim as folhas persistentes são de consistência dura e firme e apresentam as seguintes particularidades: cutícula espessa, impermeável, mesófilo pouco lacunoso, textura fibrosa, presença de esclereídeos, estômatos localizados na face inferior do limbo.

Fora desta estrutura foliar típica, podemos distinguir 4 casos:

- Folhas pequenas, com estrutura anfistomática: certas Dacrydium, os gêneros Falcatifolium, Dacrycarpus e Acmopyle. Em Acmopyle podemos distinguir vários tipos de folhas, sendo 2 tipos principais: folhas escamosas e folhas principais assimiladoras, lineares, achatadas bilateralmente, dísticas, existindo folhas intermediárias.

- Folhas lineares, aciculares ou ligeiramente lanceoladas, achatadas, com estrutura anfi ou hipostomática: Phyllocladus, Saxegothaea, Stachycarpus, algumas plantas do grupo eupodocarpos (rostrata, perrieri, totara...).

- Folhas longas com desenvolvidos limbos ovais, plurinérveas, paralelinérveas (simulando estranhamente a folha de uma monocotiledônea), com estrutura anfi ou hipostomática: secção nagei dos Podocarpus.

- Folhas pequenas, escamiformes, simulando as folhas escamosas das $\mathrm{Cu}$ pressaceae: Pherosphaera, alguns Dacrydium, Dacrycarpus, Acmopyle e em Podocarpus usta. O caso de Microcachrys é original: folhas espiraladas são inseridas de tal maneira que parecem dispostas em verticilos opostos, decussadas sobre 4 fileiras, daí o nome da espécie $M$. tetragona. 
É preciso salientar que estas Podocarpaceae com folhas de tipo cupressoide foram fonte de erro no passado: GAUSSEN cita o caso de Podocarpus dieffenbachii desenhado por HOOKER e onde a anatomia mostrou que se tratava de Veronica tetragona. Nós citamos o exemplo de uma forma jovem de $P$. rostrata, coletada por HUBERT e CAPURON ao sul do Maciço de Tsaratanana (Madagascar), $\mathrm{n}^{\circ} 25020$ Herbarium Musei Parisiensis e onde a anatomia mostrou que se tratava de uma dicotiledônea apresentando uma surpreendente convergência de forma com aquela de uma jovem plântula de Gimnosperma.

Certos gêneros possuem folhas de 2 tipos: Dacrycarpus e. Acmopyle. Em Dacrycarpus, is ramos longos (auxiblastos) portam folhas aciculares ou escamosas e os mesoblastos com crescimento limitado, partam folhas longas, subuladas, com inserção dística, estendidas num plano, chatas e comfrimidas lateralmente. Estes mesoblastos são caducos por inteiro.

Em Acmopyle, gênero muito raro da Nova Caledonia e das Ilhas Fidji, reencontramos estes 2 tipos de ramos, uns portando folhas escamiformes e cutros folhas subulares. Foi SAHNI (1920) que mostrou a originalidade destas últimas: o limbo foliar é situado acima e abaixo do feixe libero-lenhoso.

Fora do caso de Microcachrys, existem outros Podocarpus onde as folhas espiraladas podem aparecer como subverticiladas por 2, dísticas num plano por torção da base foliar. Dizemos que a filotaxia é bijugada, subdecussada com 4 geratrizes espiraladas. Sobre os jovens brotos a tendência da filotaxia é se tornar alterna.

- Exemplo africano: Afrocarpus (A. mannii)

- Exemplo americano: Podocarpus rospigliosii da Venezuela

- Exemplo da Australasia: Podocarpus secção nageia

Nos 2 primeiros exemplos, as folhas subopostas de um pseudoverticilo, vão mostrar para uma orientação vascular normal e para outra uma orièntação inversa (FLORIN, 1931, p.193).

Para o último exemplo da série nageia ( $P$. blumei e $P$. wallichiana), somente os ramos plagiotrópicos portam 2 tipos de folhas em filas opostas: as de um lado estão em posição normal, as do outro estão em posição isobilateral, recebendo a luz sobre as 2 faces. A estrutura foliar nestes 3 exemplos é anfistomática e as células do parênquima paliçádico se repartem sobre as 2 faces.

Uma observação original foi feita sobre 2 espécies de Podocarpus: $P$. madagascariensis e $P$. elata da Austrália (WOLTZ, não publicado).. Trata-se de folhas adultas, binérveas possuindo somente um broto axilar. No início o traço vascular foliar é único, mas depois há a formação de 2 nervuras por dicotomia. Podemos então encontrar excepcionalmente nas espécies que possuem normalmente folhas uninérveas, uma tendência a binervação, anunciando assim à espécies com folhas polinérveas da Insulíndia e do Japão. 


\section{Anatomia foliar}

- Escolha do material e métodos.

\section{1) Material}

A escolha do tipo de folha e sua idade são de grande importância; a determinação da espécie deve ser certeira. Mesmo atualmente, reina uma grande confusão entre alguns Herbários e Jardins Botânicos: certas espécies que circulam com estes nomes são errôneas: $P$. macrophylla (China), $P$. neriifolia (Nepal), $P$. coriacea (Antilhas), P. polystachya (Singapura), P. latifolia (Sri-Lanka), $P$. purdieanea (Jamaica), $P$. spinulosa (Austrália) são todas referentes à $P$. elata da Austrália, muito decorativa e robusta, mas que foi introduzida nestes diversos países. É preciso então corroborar o exame de uma presumida espécie por cortes feitos em amostras de diferentes procedências e coletores. Se dispusermos somente de uma espécie certa, é necessário examinar várias folhas. É preciso evitar folhas próximas dos órgãos reprodutores pois estas são freqüentemente reduzidas em relação às folhas vegetativas normais e estão submetidas à influência de hormônios sexuais. Assim, é preciso ter cuidado com a escolha do material e só comparar folhas comparáveis: tomar sempre amostras foliares adultas que estiverem em ramos do ano, chegadas ao termo de seu crescimento.

\section{2) Métodos}

Os cortes foram feitos à̀-mão, depois, após inclusão na parafina, ao micrótomo, confeccionando assim delgadas lâminas seriadas. Os cortes foram préparadoß com Bálsamo do Canadá. O nível estudado foi sempre o 1/3 inferior da folha. A coloração de Carmin-Verde de Miranda foi abandonada pela de HematoxilinaSafranina-Azul de Anilina (Azul da China). Esta última tem a vantagem de dar com o mínimo de artefatos possíveis, para amostras frescas, uma idéia precisa do aparelho secretor com coloração vermelha-alaranjada dos produtos secretados: óleo-resinas e taninos. Se se tratam de amostras de herbários, estas devem ser previamente hidratadas durante 48 horas com utilização de um agente umidificante. As amostras frescas, antes da obtenção dos cortes, devem ser fixados e conservados em líquido CRAF' III assim composto: formol 10\%, ácido acético à $10 \%$ (comercial): $20 \%$, ácido crômico à $1 \%$ : $30 \%$, água destilada: $40 \%$.

\section{- Estrutura anatômica "tipo" da folha de Podocarpus} condutor.

O exame da secção foliar transversal, mostra a importância do aparelho

A nervura pode ser proeminente ou côncova e apresentar algumas vezes um sulco longitudinal mediano superior. Este caráter de nervaçäo foi utilizado por GRAY na descrição de espécies e para a identificação de espécies de Herbários. Sem entrar em detalhes, a existência e a localização dos tecidos 
de transfusão, dos estômatos, dos escleritos, o número de nervuras, a forma foliar mas sobretudo o número e a disposição dos feixes resiníferos foram aqui levados em consideração e discutidos.

\section{1) Tecidos ligados ao aparelho condutor}

Em corte, o feixe vascular tem uma forma característica, destendido segundo a linha de separação do xilema-floema. A presença de fibras esclerosadas em posição intraliberiana é constante. $O$ feixe vascular é rodeado de fibras esclerosadas isoladas. Entre a nervura e a margem foliar se encontram 2 tecidos importantes: o tecido de transfusão (T.T.) e o tecido de transfusão acessório (T.T.A.), chamado também de hidrosteroma transversal.

\section{a) $\mathrm{O}$ tecido de Transfusão}

Todas as espécies de gimnospermas e de dicotiledôneas primitivas, como as Casuarinaceae do hemisfério austral, possuem este tecido. Ele está situado envolvendo o feixe, mas pode ser reduzido em Dacrycarpus e Stachycarpus, desenvolvido em $S$. amara e na secção Eupodocarpus, estendido até o meio do limbo em Afrocarpus e Polypodiopsis. As células deste tecido são mais ou menos isodiamétricas e se parecem com traqueídeos por suas aréolas e seus espessamentos espiralados. Ele teria, segundo BOUREAU (1954), uma dupla origem.

- "Ele pode provir da transformação do xilema centrípeto a apresentar assim um certo interesse ao ponto de vista evolutivo."

- "Ele pode aparecer em um ponto qualquer, muitas vezes por influência do meio, na seqüência de uma diferenciação adaptativa sobre o luar do parênquima fundamental, sem que o possamos homologar à um tecido condutor normalmente diferenciado no mesmo lugar em outras espécies."

b) O tecido de Transfusão acessório "hidrosteroma"

Ele está evidentemente ligado ao desenvolvimento do limbo em folhas uninérveas. Em dicotiledôneas, existem ramificações das nervuras para irrigar o limbo foliar. Aqui a irrigação se faz por intermđio deste tecido especial, relacionando o tecido de transfusão com o clorênquima até as margens foliares. Podemos pensar que a evolução pôde se dar a partir de folhas estreitas até folhas largas, com aparecimento do hidrosteroma. Este tecido teria um papel na sustentação do limbo e na condução de líquidos. As células do hidrosteroma são orientadas perpendicularmente às células do tecido de transfusão. São células alongadas, esclerosadas, onde as extremidades apresentam pontuações características em forma de fendas “oculiformes", algumas vezes são verdadeiras pequenas aréolas. Este tecido pode estar ausente em Afrocarpus. 
2) O limbo foliar

- A epiderme da face superior (adaxial) é revestida de uma espessa cutícula que falta em folhas anfistomáticas (Afrocarpus e Podocarpus secção Polypodiopsis).

- A sub-epiderme (hipoderme de certos autores) é essencialmente constituída de fibras esclerosadas contíguas. Ela é ausente em Falcatifolium e Stachycarpus e apresenta uma estrutura descontínua em Afrocarpus.

- O clorênquima pode aparecer sob forma paliçádica nas 2 faces da folha se a estrutura é anfistomática. No caso mais freqüente (estrutura hipostomática), o parênquima paliçádico se reduz a 2 ou 3 camadas celulares e não está em relação direta com o colênquima lacunoso da face inferior (abaxial), salvo nas margens da folha. $O$ tecido de transfusão e o tecido de transfusão acessório os separam.

- Os esclereídeos, chamados também idioblastos ou escleritos, são elementos celulares freqüentemente característicos de mesófilo. São células esclerosadas que se dividem em 2 tipos, se bem que uma classificação baseada em suas formas seja dificil de estabelecer, já que ocorrem numerosas transições.

- Esclereídeos vasculares ligados ao feixe, mas situados no limite do feixe e do mesófilo clorofilado: são células curtas, isodiamétricas com espessas paredes, com lumen aberto, ou fibras-esclereídeos de grande tamanho, com espessas paredes mas com lumen reduzido.

- Esclereídeos auxiliares: Em algumas espécies, as células do clorênquima paliçádico são modificadas, pela presença em seu seio de esclereídeos de grande diâmetro, isolados, com paredes espessas e esclerosadas, como $P$. madagascariensis. Estas células são recơnhecíveis pela sua posição paralela em corte transversal e pela sua tendência a se ramificar ou apresentar apêndices digitados, acentuando assim o caráter esclerificado da folha.

\section{3) Os tecidos secretores}

Os tecidos secretores devem ser examinados particularmente. Eles elaboram as óleo-resinas (óleos essenciais e resinas).

a) Os taninos

Eles se encontram nas células secretoras dilatadas em relação às células circundantes, o produto secretado é armazenado em um grande vacúolo. Os compostos tânicos são postos em evidência no material fresco através de reações simples: coloração preta-azulada por cloreto férrico, parda por bicromato de potássio, vermelha por hidróxido de potássio à $40 \%$, azul escuro por azul de metileno. As células são particularmente localizadas na bainha parenquimatosa envolvendo o feixe libero-lenhoso e poderiam constituir uma placa antiséptica natural. 
b) Os canais resiníferos

Sua formação é esquizógena: na origem, células secretoras alongadas, agrupadas no seio do parênquima reservam entre elas um meato intercelular. As células epiteliais assim formadas derramam produtos óleo-resinosos no meato, que toma o aspecto característico de um canal. Falta ser feito um estudo detalhado de gênese do sistema resinífero para o conjunto das Podocarpales, mais particularmente para o gênero Stachycarpus.

Uma secção de uma folha "tipo" de Podocarpus mostra sempre, sob o feixe vascular, pelo menos um feixe resinífero em posição adliberiana. A localização e o aumento do número de feixes resiníferos constituem bons caracteres para distinguir secções ou mesmo espécies. Para o conjunto das Podocarpales, existem variações, elas são menores.

Como para as Abietaceae, de FERRE (1952), existem feixes principais e acessórios. A presença dos primeiros é constante nas folhas desde suas formações, eles terminam na parte distal da folha. Os feixes acessórios podem não aparecer ou serem de aparecimento tardio, são curtos e independentes uns dos outros.

De acordo com o número e a posição dos feixes resiníferos na folha, distinguimos os seguintes casos:

- Um só feixe adliberiano: é o caso dos gêneros Saxegothaea, Phyllocladus, Pherosphaera, Microcachrys, Dacrydium (salvo fonkii da Patagônia), Falcatifolium, Stachycarpus, Afrocarpus, Acmopyle. Dacrycarpus, os Eupodocarpus americanos (Subsecção 4 de GAUSSEN) agrupando 30 espécies, e os da subsecção 3 ou 7, espécies do Chile, Nova Zelândia, Nova Gales do Sul e Tasmânia.

- 3 feixes adliberianos: o feixe de condução médio é acompanhado de 2 feixes laterais, é o caso da maioria dos Eudopocarpus (subsecção 5) da Australásia, agrupando aproximadamente 40 espécies.

- Caso original do Podocarpus da América Central (secção Polypodiopsis): $P$. rospigliosii que possui de 1 a 3 adliberianos aos quais se juntam no mesófilo 2 a 6 feixes isolados.

-5 a 10 feixes, compreendendo 3 a 5 feixes adliberianos e 2 a 5 feixes abaixo do que está em posição adaxial: caso dos Eupodocarpus da subsecção 6, das espćies do Pacífico (com 3 espécies) 2 das Ilhas Fidji e 1 das Ilhas Tonga. $P$. degeneri considerada como uma variedade de $P$. neriifolia (subsecção 5) das Ilhas Fidji, poderia ser incluída na subsecção 6 e se juntar à $P$. decipiens.

- 11 a 23 feixes: caso de 2 espécies de Eupodocarpus de Madagascar (subsecção 1):

- 3 feixes de condução, 2 marginais, 6 a 10 no mesófilo, $P$. rostrata.

- 3 a 7 feixes de condução, 2 marginais, 12 a 14 no mesófilo, $P$. woltzii.

-5 feixes: aos 3 feixes adliberianos, é preciso somar 2 feixes marginais situados na extremidade do limbo foliar, é o caso dos Eupodocarpus africano-madagasquenhos com 10 espécies. 
c) existe uma relação entre os feixes foliares e o sistema resinífero do caule?

Nós tomamos 2 exemplos:

- Podocarpus madagascariensis var. procera mostra que no início da formação do estelo no caule, os 3 feixes da condução já existem. Os feixes marginais foliares se formam após divisão dos feixes corticais que margeiam o estelo. Assim os 5 feixes definitivos são formados no caule e acompanham o estelo ao curso do trajeto da folha na casca. Existe continuidade do sistema resinífero do caule e da folha, $P$. rostrata e $P$. woltzii mostram também esta continuidade.

- Em Podocarpus rospigliosii da Venezuela, existe continuidade entre os feixes de condução: normalmente o feixe fascicular é único, excepcionalmente pode ser bi ou trifurcado. Os feixes supranumerários do mesófilo podem aparecer tardiamente. Eles são independentes uns dos ontros e não têm ligação com os de condução.

\section{Discussão}

Lembramos que o gênero Podocarpus (senso stricto) possui verdadeiras folhas. Os outros gêneros de podocarpales apresentam um polimofismo foliar:

- Folhas jovens, curtas em forma de agulhas, dos Phyllocladus, são axilares de complexos filoclados. Estes, transformados em ramos achatados clorofilados portam enfim folhas adultas, órgãos aclorofilados reduzidos à minúsculas escamas.

- Folhas primordiais de. Dacrycarpus, longas e aciculares são axilares de auxiblastos portadores de escamas imbricadas e espiraladas. Estas últimas, por sua vez, são axilares de mesoblastos característicos por suas folhas dísticas em agulhas.

- Os Dacrydium mostram que às folhas jovens em forma de agulhas se sucedem bruscamente folhas adultas escamosas e carnudas. Uma espécie, $D$. cupressinum, a mais austral da Nova Zelândia, não apresenta folhas escamosas na fase adulta. As folhas "definitivas" parecem ser a continuação de uma fase jovem, são folhas em forma de agulhas curtas $(0,5 \times 0,1 \mathrm{~cm})$. A passagem de folhas primordiais cilíndricas decorrentes $(1 \times 0,1 \mathrm{~cm})$ para folhas adultas é progressiva, sendo que estas últimas conservam um aspecto juvenil.

Nós vimos que os cotilédones "primitivos" caracterizariam as espécies mais austrais de Podocarpales (WOLTZ, 1986). Todas estas espécies têm folhas adultas aciculares, onde a estrutura anatômica é relativamente simples. Assim, à origem, podemos pensar que a folha simples do tipo "agulha" foi sobreposta, representando a folha dita "primitiva". A partir desta estrutura, teria ocorrido uma passagem à uma folha longa, larga e com limbo desenvolvido, mais complexa em sua anatomia. Esta passagem seria um sinal visível de uma adaptação secundária que marcaria a etapa "evoluída". Alguns gêneros ou espécies mostram uma redução de certos caracteres "evoluídos", uma tendência à simplificação em direção ao tipo "primitivo". Isto seria uma "supraevolução", já que outros caracteres, ao contrário, parecem excessivos em seu desenvolvimento. Estes 
últimos evidenciam os sinais de uma degenerescência de fim de filo ou de senilidade.

Assim, após o processamento da etapa de evolução máxima, pareceria adequado considerar no vegetal, o fenômeno dito "supra-evolução" (de acordo com terminologia de GAUSSEN), caracterizado por um retorno parcial ou acentuado em direção a uma forma primitiva.

A Tabela I resume os principais caracteres morfológicos e anatômicos da folha que participariam ao senso da evolução das Podocarpales.

Esta maneira de encarar as coisas certamente acarretará uma necessidade de retoques em estudos ulteriores. Somos conscientes da fragilidade dos critérios propostos para a escolha do senso evolutivo. Isto é uma hipótese, mas ela tem o mérito de permitir a classificação, de uma maneira relativamente satisfatória, um grande número de fatos observados, mesmo se atualmente a imprecisão de nossos conhecimentos seja notória para certos gêneros e espécies quanto à evolução de outros órgãos, em particular os sexuais (certas espécies são conhcidas somente à partir de seus órgãos vegetativos, caule e folhas).

$O$ estudo dos feixes resiníferos nos parece de grande importância em Podocarpales e pelo que sabemos, não foi ainda feito. Ele favorece a idéia de um retorno ancestral. Em particular o caráter representado pela multiplicação dos feixes pode ser considerado como "primitivo", já que a redução iria no sentido da evolução. No limite, não há mais que um só feixe secretor adliberiano. Este pensamento foi explicitado por de FERRE (1952) para as Abietaceae no hemisfério norte.

Da mesma maneira, na ordem Taxales, a seguinte sucessão é conhecida como indo no sentido de evolução:

- Em Cephalotaxus, existem feixes resiníferos na casca e algumas vezes uns no parênquima medular da axe da inflorescência. Sabemos que talvez, sob influência de hormônios, o órgão reprodutor pode fazer aparecer localmente imagens que lembram condições ancestrais.

- Em Taxus, somente folhas jovens esboçam um feixe que regride rapidamente com a idade (CHAUVEAUD, 1982).

- Enfim, as células resiníferas se encontram na madeira de Torreya e no periciclo de Austrotaxus (WOLTZ, 1982).

- Podemos então tentar aplicar esta noção de evolução do sistema secretor às Podocarpales do hemisfério sul.

É bom salientar que os feixes são suscetíveis a variações notáveis do diâmetro, ao curso do trajeto longitudinal foliar. Por convençâo, vamos sempre dar os valores para o nível correspondente ao terço inferior do órgão foliar.

1) Comparação entre os gêneros e espécies africano-madagasquenhos:

a) Espécies mađagasquenhas "primitivas"

Para Madagascar, 2 espécies se separam claramente de outras espécies de Eupodocarpus, as da subseç̧ão 1: P. rostrata (folhas em "agulhas") e $P$. woltzii (folha com limbo desenvolvido). A originalidade anatômica destas 
2 espécies é devida ao fato da abundância de feixes resiníferos, nesta ótica, elas mostram uma evidente marca de arcaísmo.

Uma tendência à obliteração dos feixes marginais na parte distal e a presença de um só feixe adliberania pode ser observado em $P$. perrieri. Esta mesma tendência se confirma para as espécies africanas: $P$. milanjiana, $P$. ensicu$l a, P$. elongata. Para estas espécies, o diâmetro do feixe médio adliberiano é sensivelmente o mesmo e pode se aproximar de 2 espécies do sudeste do Brasil: $P$. lambertii e $P$. sellowii.

Podemos formular a seguinte hipótese: a origem dos Podocarpus africanos e madagasquenhos poderia ser encontrada entre os descendentes de um ancestral comum, representado atualmente por $P$. rostrata de Madagascar. Esta última espécie, caracterizada por suas folhas em agulhas, seus numerosos feixes resiníferos, seu porte ericóide, é relictual por excelência, refugiada sobre as altas montanhas, nas florestas dos cimos. Não é certa a existência desta espécie hoje na grande ilha. Alguns exemplares e foram assinalados no Maciço de Tsaratanana por MORAT e CAPURON pela última vez em 1966. Infelizmente, as sementes desta espécie raríssima não foram jamais coletadas.

b) A linhagem Afrocarpus (Cf. GAUSSEN e WOLTZ, 1979)

A linhagem dos Afrocarpus pôde se diversificar secundariamente à partir do material original $P$. perrieri que possui folhas em agulhas por aquisição de um limbo desenvolvido, do tecido de transfusão (T.T.), do tecido de transfusão acessório (T.T.A.), de esclereídeos e da estrutura anfistomática. Uma só espécie é descendente desta linha de Madagascar: A. gaussenii. Sua anatomia se explicaria por sua situação à leste de "Périnet", numa região bioclimática subequatorial de média altitude, particularmente chuvosa (pluviométria superior à $2000 \mathrm{~mm}$ por ano). Assim, a planta teria perdido seu caráter sérico. A linha Afrocarpus é melhor representada na África com 6 espécies, somente A. falcata é austral, as outras são da África Central Oriental. A. mannii, com a perda do T.T.A. e dos esclereídeos, atinje o limite setentrional na África Central do Oeste.

Assim, a partir dos altos picos de montanhas de Madagascar, a espécie “arcaica" $P$. rostrata poderia ser a origem da divisão e da diversificação de todos os outros Podocarpus da ilha e do continente próximo.

Haveriam 2 linhagens evolutivas "A" e "B", cada linhagem sendo influenciada por via austral e por via oriental africana. Esta última passando em seguida na África central para terminar sobre os montes da África equatorial atlântica (Ilha de Fernando Póo).

Pertencem a linhagem " $\mathrm{A}$ " as espécies de Afrocarpus com folhas anfistomáticas derivando do tipo $P$. rostrata por perda de feixes resiníferos, salvo um:

1. A. gaussenii, Madagascar

2. A. gracilior, Etiópia-Quênia

3. A. dawei, Uganda.

4. A. usambariensis, Congc.

5. A. mannii, São Tomé-Camarōes.

6. A. falcata, África do Sul.

7. A. gracillima, África do Sul. 
As espécies 2, 3, 4, 5 são influenciadas por via oriental, as espécies 6 e 7 por via austral. As espécies 1 e 5 são separadas depois de muito tempo do grupo africano. É preciso investigar uma longínqua origem no Gondwana.

\section{c) A linhagem Eupodocarpus}

A linhagem "B" é representada por 12 espécies e variedades de Eupodocarpus com folhas hipostomáticas da subsecção 2 de GAUSSEN. Estas espécies possuem ainda 5 feixes secretores ( 3 adiliberianos, 2 marginais), portanto menos evoluídas que as espécies da linhagem " $A$ ". Nos temos:

1. P. madagascariensis, Madagascar.

2. P. madagascariensis var. rotunda, Madagascar.

3. $P$. madagascariensis var. procera, Madagascar.

4. P. perrieri, Madagascar.

5. $P$. humbertii, Madagascar.

6. $P$. capuronii, Madagascar.

7. P. milanjiana, África Central-Camarões.

8. P. ensicula, África Central-Camarões.

9. P. henkelii, África do Sul.

10. P. latifolia, África do Sul.

11. P. elongata, África do Sul.

12. P. latior, África do Sul.

As espécies 1 a 6 são madagasquenhas, $P$. madagascariensis é afim de $P$. henkelii. As espécies 7 e 8 são influenciadas por via oriental, as espécies $9,10,11$ e 12 por via austral.

Nos 2 casos "A" e "B", podemos também considerar a possibilidade de migraçōes de montanhas do sul em direção ao norte. Estas poderiam ter sido facilitadas por variaçöes climáticas, que a um dado momento, teriam baixado os limites altitudinais das espécies. A maior parte das estações africanas correspondem a ilhas continentais (picos de altas montanhas) ou a plataformas de altitude média onde o clima se aproxima do clima austral temperado úmido.

\section{2) Comparação entre os gêneros e espécies americanas}

As espécies americanas se referem a duas famílas: Saxegothaeaceae, monogenérica, monoespecífica endêmica dos Andes meridionais e Podocarpaceae bem representada com 39 espécies divididas em três gêneros e duas secções (da Patagônia em direção ao Equador):

- Gênero Dacrydium com uma só espécie: $D$. fonkii endêmica dos andes meridionais.

- Gênero Stachycarpus com sete espécies, da Patagônia aos Andes equatoriais (as espécies equatoriais são afins).

- Gênero Podocarpus, secção Eudopocarpus, dos Andes meridionais ao hemisfério norte.

- Gênero Podocarpus, secção Polypodiopsis, com uma só espécie: P. rospigliosii da Venezuela. 
Todas as espécies americanas são reconhecíveis pela presença de um só feixe fascicular médio adliberiano. Entre as Podocarpales, Dacrydium fonkii está à parte, mesmo entre as espécies do gênero (essencialmente australasianas): ela não possui sistema resinífero... e por este caráter, a espécie mostraria-se como a fase mais evoluída.

$P$. rospigliosii é o único representante americano da secção Polypodiopsis, as outras espécies se acham nas Ilhas Sonda até as Ilhas Fidji. Ela poderia ter uma ligação com Afrocarpus, em particular com A. mannii. As folhas são subdísticas, anfistomáticas e sem T.T.A.. A presença de feixes acessórios no mesófilo de $P$. rospigliosii pode ser de aparecimento tardio ao curso da morfogênese foliar. As duas espécies estão na mesma latitude. É notável observar, de ambos os lados do Atlântico, a distribuição similar de Gnetum africanos e americanos. Os primeiros, da África Equatorial, com pequenas sementes são: G. africanum, G. buchholzianum, (CHEVALIER, 1951); os segundos, com sementes volumosas, originários das Guianas brasileiras e venezuelanas, são: $G$. thoa, G. schwackeanum, G. leyboldi, G. paniculatum, G. urens e G. nodoflorum (MAHESHWARI e VASIL, 1961).

$\mathrm{O}$ material original das linhagens americanas poderia ser representado por espécies com folhas tipo agulhas, de regiöes austrais: Saxegothaea, Stachycarpus andina, Podocarpus nubigena. Podemos distinguir 3 linhagens:

\section{a) Linhagem Stachycarpus}

S. andina teria dado origem, ao curso do soerguimento dos Andes no Terciário, às espécies andinas da Bolívia, Peru, Colômbia, Venezuela e mesmo da Costa Rica, com $S$. standheyi. Esta última seria de introdução recente, já que o istmo apareceu tardiamente. A conecção entre a América do Norte e do Sul foi restabelecida no Plioceno superior.

\section{b) Linhagem Eupodocarpus}

$P$. nubigena teria dado origem às espécies com limbo desenvolvido que se elevando ao longo das cordilheiras, chegam ao norte da América do Sul. Depois, pela Cordilheira de la Costa na Venezuela passam às Ilhas do Caribe e pelo Istmo do Panamá atingem o México Central. À medida que ocorre esta subida do sul em direção ao norte, é clara uma tendência de aumento do diâmetro dos feixes resiníferos. É notável que em $P$. urbanii (Jamaica) e $P$. ekmanii (Cuba) o diâmetro ultrapassa os $200 \mu \mathrm{m}$ e mesmo $500 \mu \mathrm{m}$. Paralelamente, assistimos a um desenvolivimento considerável dos esclereídeos correspondentes: $300 \times 60 \mu \mathrm{m}$ (P. urbanii); $300 \times 40 \mu \mathrm{m}$ (P. ekmanii). Estes caracteres anatômicos de espécies chegadas ao limite setentrional do gênero, poderiam ser interpretados como o resultado de uma certa degenerescência ou de senilidade, anunciando um fim de filo. 
c) Espécies do Escudo das Guianas

Quatro espécies endêmicas do sudeste da Venezuela: $P$. steyemarkii, $P$ tepuiensis, $P$. roraimae, $P$. magnifolia, estão localizadas sobre altos picos do Escudo das Guianas (do Gondwana). Logicamente, estas espécies seriam mais "antigas" que aquelas que migraram pelos Andes. Talvez elas sejam relíquias do Cretáceo.

É possível que as 2 espécies endêmicas do sudeste brasileiro, $P$. lambertii e $P$. sellowii, estejam também ligadas à estas do Escudo das Guianas. Podemos também pensar que estas 2 espécies são próximas de algumas espécies da África do Sul, em particular $P$. elongata, pela perda de feixes marginais, caso este que pode ser excepcionalmente encontrado.

A Tabela II, permite a colocação em série, levando em conta o conjunto dos caracteres anatômicos foliares. As flechas indicam que uma espécie poderia ter originado outra espécie e que as folhas correspondentes podem ser postas em série.

3) Comparação entre os gêneros e espécies da Austrália

Nós abordamos uma regiâo geográfica que permite uma explosão de espécies, graças ao clima equatorial que reina na Insulíndia. Certas espécies são estreitamente ligadas ao contexto geográfico: ilhas, picos de altas montanhas e são de fato, afins. No passado, é provável que os autores, por laxismo, tenham exagerado na enumeração de espécies. A isto, soma-se um problema de sinonímia quase inextricável! Nestas condições, o problema apresentado pela evolução e a possível filiação das espécies é complexo.

Este território é imenso e cobre do sul ao norte da Nova Zelândia até o Japão, de oeste à leste de Assam até as Ilhas Tonga. Nós encontramos aí 3 famílas, 9 secções ou subsecções as quais eu enumero as espécies correspondentes: Phyllocladaceae (7), Pherosphaeraceae (1), Podocarpaceae (Microcachrys (1), Stachycarpus (5), Falcatifolium (4),, Acmopyle' (3), Dacrycarpus (4), Microcarpus (1), (espécie parasita), Nageia (6), Polypodiopsis (4), Eupodocarpus (51)). No total, os diferentes taxons são representados por cerca de 97 espécies. Nós deixamos deliberadamente de lado o exame detalhado dos gêneros Phyllocladus, Dacrycarpus e Dacrydium, por falta de material confiável, além do mais o gênero Dacrydium mereceria uma revisão morfológica e anatômica completa.

No exame anatômico foliar de Podocarpus (s.1.), 2 categorias se impöem: espécies com folhas uninérveas e espécies polinérveas.

a) Folhas uninérveas.

- Folha em agulha ou com limbo estreito, possuindo um só feixe resinífero.

Estas espécies com folhas em agulha ou onde o limbo é pouco desenvolvido são geralmente localizadas em latitudes mais baixas: Stachycarpus spicata, $S$. ferruginea, Podocarpus acutifolia (Nova Zelândia), P. lawrencii, S. ladei, P. spinulosa (Tasmânia Austrália), ou isoladas na Nova Caledônia: $P$. gnidioides 
e $S$. ferruginoides. Em particular 3 espécies afins são notáveis: $S$. ferruginea, $S$. ladei, $S$. ferruginoides e mostram a existência de uma estreita ligação florística entre a Nova Zelândia, Austrália e a Nova Caledônia, elas só se diferenciam pelo número de idioblastos presentes em corte transversal da folha que aumenta de acordo com a latitude. Assim, podemos pensar que eles resultam de uma adaptação secundária: ausência de idioblastos: $S$. ferruginea (Nova Zelândia); 2-3: S. ladei (Austrália); 15-18: $S$. ferruginoides (Nova Caledônia). níferos.

- Folhas longas à limbo desenvolvido, apresentando de 8 à 5 feixes resi-

Entre estas folhas longas com limbo largo, uma dezena de espécies são todas originais quanto a sua anatomia, trata-se de $P$. longefoliolata, $P$. decumbens, $P$. polysperma (Nova Caledônia); $P$. ledermannii (Bornéu, Nova Guiné); $P$. ridleyi (Península da Malásia, Bornéu, Nova Guiné). A secção foliar mostra uma tendência à multiplicação dos feixes resiníferos, circundando (acima e abaixo) o feixe condutor. Isto não sem lembrar a estrutura encontrada à Madagascar em $P$. rostrata e $P$. woltzii, excepcionalmente em $P$. madagascariensis, com 5 feixes em lugar de 3 normalmente.

Esta imagem original foi assinalada por GRAY (1958) em P. ridleyi "A folha mostra 5 feixes vasculares resiníferos, os dois mais extremos estão freqüentemente localizados no tecido de transfusão em cada lado do feixe'". Os dois feixes adliberianos mais marginais apresentam uma tendência a atravessar o tecido de transfusão para ocupar uma posição adaxial, face ao xilema. Esta situação traz um problema de organogênese: se os tecidos representados pelo sistema resinífero e o tecido de transfusão podem ser considerados como resultantes de caracteres arcaicos, sua gênese é radicalmente oposta. As células secretoras no órgão foliar são orientadás no sentido horizontal, elas podem se alongar e possuem um pequeno diâmetro, as do T.T. são isodiamétricas e não podem se alongar, são traqueídeos com ornamentações lignificadas e com aréolas. Existe então confusão entre estes dois tecidos desde o início da organogênese foliar. $\mathrm{O}$ problema fica a ser estudado, mas o material é raríssimo e nós nunca obtivemos amostras vivas.

Duas espécies australianas são interessantes. Elas mostram uma certa variação no seu sistema resinífero, dando assim o sentido possível da evolução, por redução do número de feixes na folha: de 5 à 3 depois à 1 .

- Caso de P. elata, espécie de Nova Gales do Sul e de Queensland.

Normalmente a espécie é caracterizada por 3 feixes vasculares adliberianos. Entretanto algumas espécies apresentam 5 feixes, os dois laterais localizam-se perto ou dentro do T.T., em duas outras amostras coletadas (de indivíduos diferentes) no Monte Spurgeon (BROW 3117 e ANON 10545) mostram um só feixe adliberiano.

- Caso de $P$. disperma

Espécie localizada em Queesland, planalto Atherton, $1600 \mathrm{~m}$, perto de Cairns, com folhas longas e largas (18 x 3cm). GRAY (1958) relata: "secções transversais de folhas mostram usualmente 3 feixes vasculares resiníferos (raramente 1 ou 5)". A amostra estudada (de LAUBENFELS $n^{\circ}$ P.465), confirma esta observação. 
A Tabela III resume a colocação em série das espécies mais notáveis. Ela é baseada na redução do sistema resinífero, sinal de evolução das espécies.

Podemos pensar que as espécies com folhas longas, limbo largo e com numerosos feixes resiníferos ao redor do feixe vascular, são as mais arcaicas. $\mathrm{O}$ foco atual de distribuição destas espécies abrangeria Austrália, Nova Caledônia e Ilhas Fidji. Duas espécies mais dinâmicas teriam atingido as terras situadas mais ao norte por intermédio da Nova Guiné. É o caso de $P$. ledermannii (Nova Guiné, Bornéu) e de $P$. ridleyi que encontramos em alguns altos picos da Península da Malásia (amostra estudada, de LAUBENFELS n ${ }^{\circ} 607, \mathrm{G}$. Hedan $=$ Monte Ophir, 1276 metros).

É possível que os pássaros tenham desempenhado um papel de vetor na disseminação das sementes, o que explicaria a localização destas duas espécies fora do foco original, em direção ao norte.

- Folhas longas com limbo desenvolvido apresentando três feixes resiníferos.

Todas as outras espécies da Australásia apresentam 3 feixes adberianos, nenhuma possui feixes nas margens foliares, isto se encontra em uma linhagem africana. $O$ que é notável, observando-se em direção às baixas latitudes e o equador, é a tendência de redução da abertura dos feixes. Neste ponto do globo, a evolução pareceria inversa da observada para as espécies americanas. Nós tomamos nota, para os 3 feixes, as medidas médias do diâmetro, em 3 exemplos situados a mesma latitude:

$P$. neriifolia $-25,20,22 \mu \mathrm{m}$.

P. philippinensis $-10,25,10 \mu \mathrm{m}$.

$P$. polystachya $-12,30,15 \mu \mathrm{m}$. A última espécie é original, situada no limite ou mesmo dentro de mangues. Seria uma espécie cuja adaptação à este biótopo é recente entre os Podocarpus.

Um outro exemplo, não menos notável, é dado por $P$. pilgeri das Filipinas, que possui excepcionalmente 3 feixes adliberianos onde 2 laterais se obliteram para dar um só feixe médio de $25 \mu \mathrm{m}$ de diâmetro.

b) Folhas polinérveas

As folhas são longas, largas e polinérveas. As espécies que apresentam este tipo de folha estão localizadas ao limite norte da divisão geográfica dos Podocarpus atuais, desde a Insulíndia até o Japão. A anatomia foliar mostra um grande número de nervuras (20 a 50 ou mais). Cada nervura é caracterizada por 1 só feixe liberiano, em geral de pequeno diâmetro: $20 \mu \mathrm{m}$ para $P$. nagi do Japão e 80um ao sul para $P$. fleuryi do Vietnam.

$\mathrm{O}$ T.T. é reduzido à 1 ou 2 cédulas ou mesmo ausente, o T.T.A. não existe nestas folhas.

Este tipo de folha simula estranhamente a de Agathis (Araucariaceae) elas diferem pela presença de 1 só feixe intervascular e de idioblastos de grande tamanho.

Entretanto, é preciso destacar, pela primeira vez, a existência excepcional de folhas binérveas em $P$. elata e $P$. madagascariensis. Esta possibilidade de 
uma passagem de folhas haploxílica para uma folha diploxílica por dicotomia, permitiria compreender a aquisição da polixilia, dando à essas folhas numerosas nervuras paralelas em certos Podocarpus e lembrando assim, por um retorno ancestral, por "supraevolução", a folha de Cordaite.

\section{Conclusão}

Duas tabelas de colocação em série são propostas para a evolução do gênero Podocarpus: a Tabela II concerne às espécies americanas e africano-madagasquenhas; a Tabela III às numerosas espécies da Australásia.

Estas colocações em série poderiam se relacionar às grandes linhas evolutivas chamadas filos, cada uma compreendendo uma série de taxa. Estas linhagens são independentes, transformando-se seguindo uma orientação determinada em um mesmo território geográfico. $\mathrm{Na}$ base de suas distribuições geográficas, 3 conjuntos se distinguem: grupo americano, grupo africano-madagasquenho e grupo da Australásia.

Assim, haveriam 3 linhagens americanas cujas origens poderiam se relacionar às espécies "primitivas" atuais: Saxegothaea, Stachycarpus andina, Podocarpus nubigena; 2 linhagens africano-madagasquenhas com as espécies Podocarpus rostrata e Afrocarpus e 4 linhagens na Australásia:

- A linhagem Stachycarpus

- A linhagem das espécies caracterizadas por 8 à 5 feixes, ex. $P$. decumbens.

- A linhagem das espécies caracterizadas por uma redução de feixes, passando de 3 à 1 , ex.: $P$. disperma.

- A linhagem das espécies com folhas polinérveas, onde $P$. elata poderia estar na origem.

Provavelmente não podemos estabelecer uma origem única, mas talvez uma origem múltipla (polifilética), cujas fontes longínquas seriam ainda representadas por estas espécies "primitivas". Todas estâo localizadas nas partes mais austrais de terras do hemisfério sul.

O exame da evolução vascular dos cotilédones das plântulas parece corroborar esta hipótese sustentada aqui (WOLTZ, 1986). 
TABELA I

Anatomia Foliar de Podocarpus (s.l.)

(sentido da evolução do caráter)

\begin{tabular}{|c|c|c|c|c|}
\hline & áter observado & Primitivo & Evoluído & $\begin{array}{l}\text { Aparência primitiva } \\
\text { (retorno ao primitivo }\end{array}$ \\
\hline 1 & Comprimentc & $\begin{array}{l}\text { Curta ou } \\
\text { em agulha }\end{array}$ & Longa & Longa ou escamas suculentas \\
\hline 2 & Inserçāo & Espiralada & $\begin{array}{l}\text { Espiral frouxa a } \\
\text { Pseudoverticilada. }\end{array}$ & $\begin{array}{l}\text { Dística, Subopostas, Verticilo } \\
\text { de } 4 \text {, depois } 3 \text {. }\end{array}$ \\
\hline 3 & Secção & Espessa & Achatada & $\begin{array}{l}\text { Dística, Subopostas, Verticilo } \\
\text { de } 4 \text {, depois } 3 \text {. }\end{array}$ \\
\hline 4 & Estomatos & Anfistomática & Hipostomática & Anfistomática \\
\hline 5 & & Monocíclica & Anficíclica & Anfistomática \\
\hline 6 & Limbo & Reduzido & Desenvolvido & Anfistomática \\
\hline 7 & Subepiderme & Presente & $\begin{array}{l}\text { Descontínua } \\
\text { por redução }\end{array}$ & Anfistomática \\
\hline 8 & Esclereídeos & Ausentes & Presentes & Reduzidos ou Ausentes \\
\hline 9 & Idioblastos & Ausentes & Presentes & Ausentes \\
\hline 10 & $\begin{array}{l}\text { Feixes } \\
\left.\text { Resiníferos ( } \mathbf{n}^{\circ}\right)\end{array}$ & Numerosos & $\begin{array}{l}\text { Reduzidos } \\
\text { aos principais }\end{array}$ & Multiplicação (Canais acessórios) \\
\hline 11 & $\begin{array}{l}\text { Resiníferos } \\
\text { (diâmetro) }\end{array}$ & Elevado & Reduzido & Elevado \\
\hline 12 & Feixe Vascular & Uninerveo & $\begin{array}{l}\text { Uninerveo (excep. } \\
\text { Binerveo) }\end{array}$ & Polinerveo \\
\hline 13 & $\begin{array}{l}\text { Tecido de } \\
\text { transfusão }\end{array}$ & Desenvolvido & Reduzido & Desenvolvido \\
\hline 14 & Hidrosteroma & Ausente & Desenvolvido & Ausente \\
\hline
\end{tabular}


ANATOMIA COMPARADA DAS FOLHAS E EVOLUÇĀO DAS PODOCARPINEAE

TABELA II

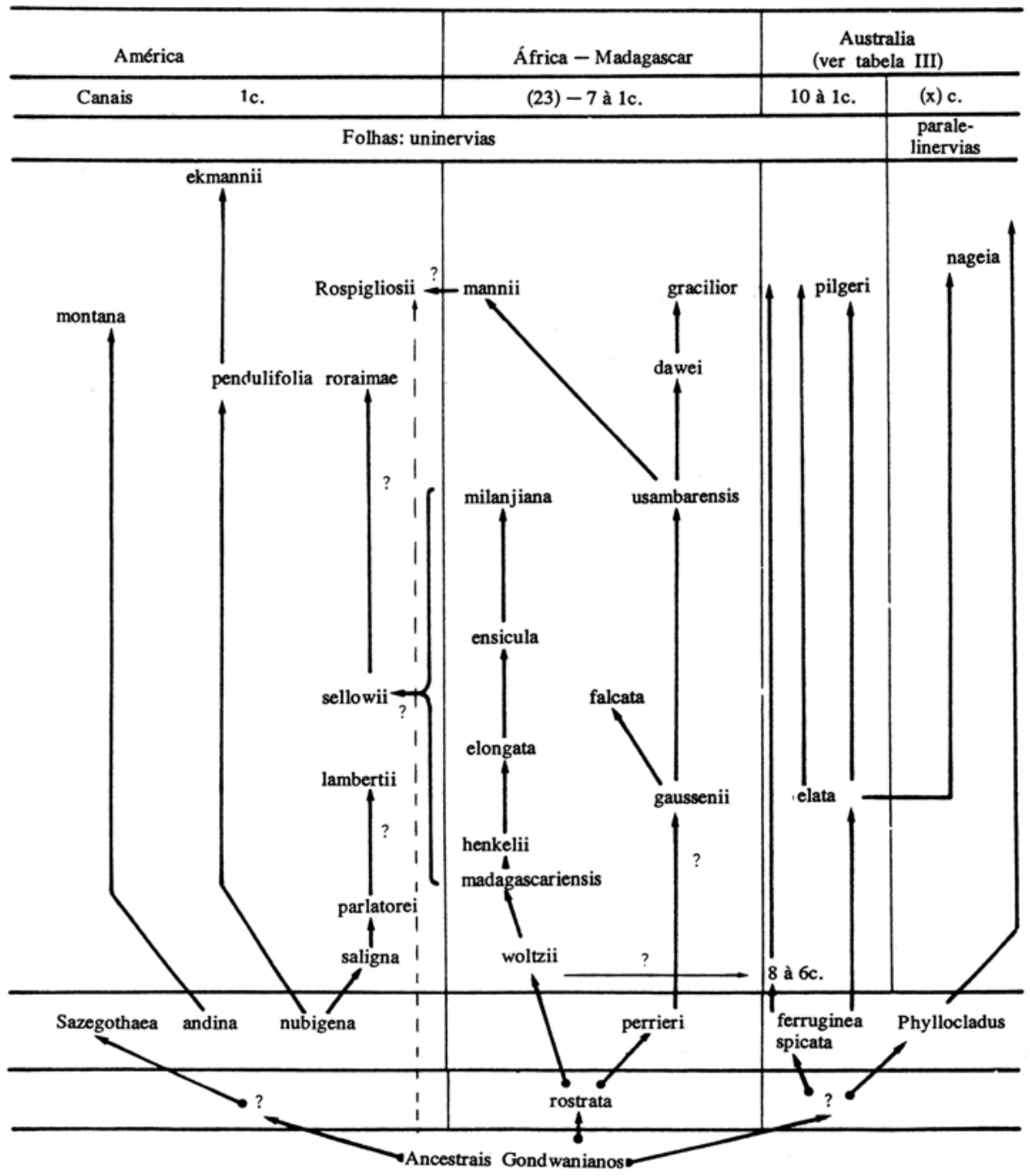


ANATOMIA COMPARADAS DAS FOLHAS E EVOLUÇĀO DAS PODOCARPINEAE

TABELA III - Evolução do gênero Podocarpus da Australásia



*O asterisco indica a posição original do par lateral dos canais resiniféros da nervura, próximos ou transversos ao tecido de transfusão. Esta imagem é relacionada as espécies madagasquenhas $-P$. rostrata, $P$. wolt zii, e excepcionalmente $P$. madagascariensis.

Origem geográfica das espécies citadas:

a) Bornéo, Hainan, Filipinas.

b) Bornéo (Mt Kinabalu).

c) Índia (Assam), Birmânia, Tailândia, China: Guizhou, Zhejiang, Sichuan, Yunnan, Kwangsi; Taiwan, Japão: Ryu-Kyu; Indochina; Filipinas, Norte Andaman, Indonésia: Mentawai, Sumatra, Java, Bornéo; Nova Guiné, Salomon, Fidji.

d) Dos mangues: Malasia, Bornéo, Filipinas, Taiwan.

e) Nova Guiné, Filipinas.

f) Queensland nas Filipinas.

g) Sumatra, Sarawak.

h) Nova Guiné, Malasia.

i) Birmania, Assam, Sul da Índia.

j) Viet-Nam até China Sul: Kwang Tung.

k) Taiwan - China: Fukien.

1) Japāo.

m) alpina, glauca, trichomanoides.

n) Nova Guiné.

o) Nova Guiné.

p) Bornéo. 


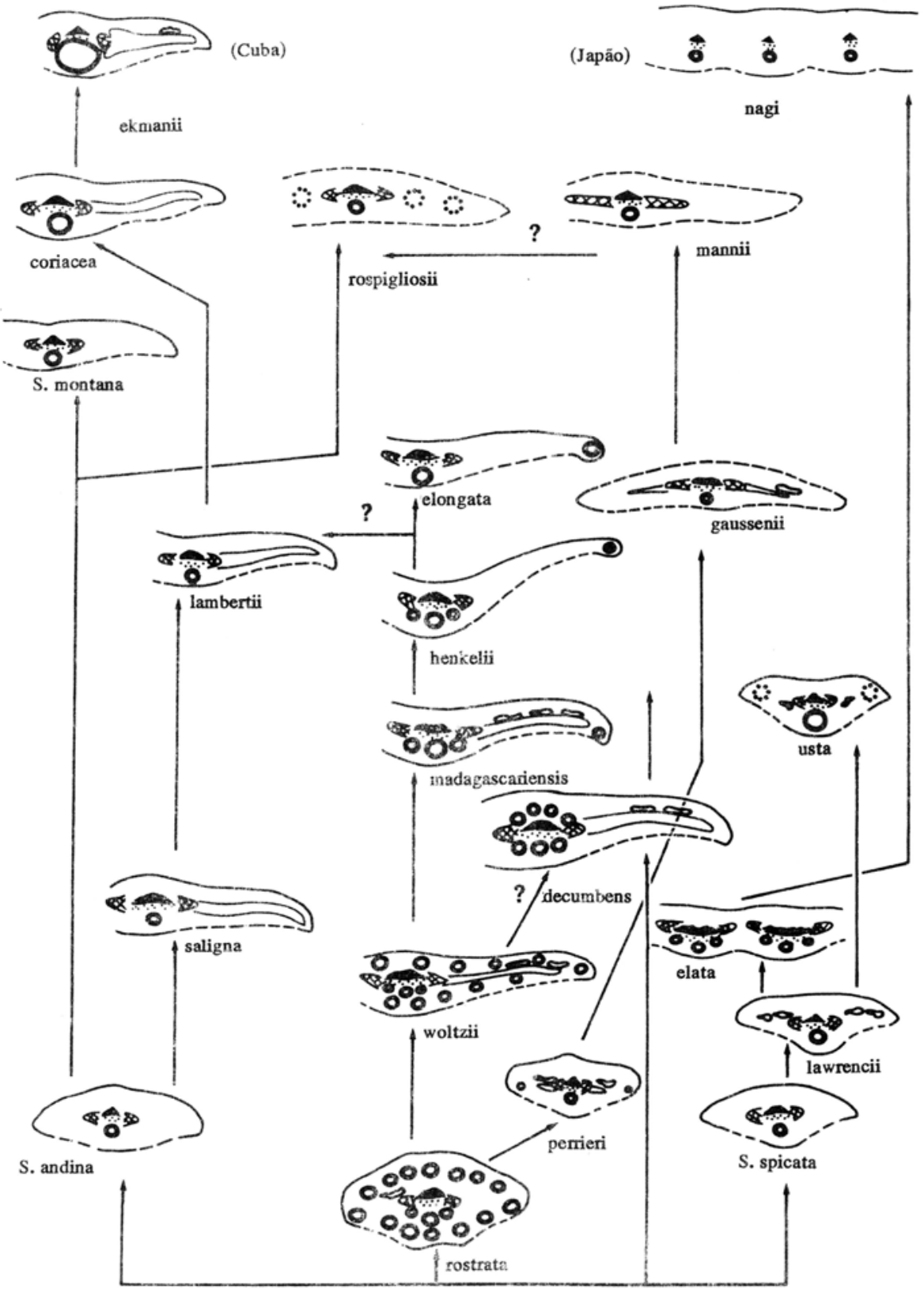

"Ancestrais goncwanianos austrais 


\section{Bibliografia}

BAKER R.T. \& SMITH H.G. 1910. A research on the pines of Australia. Techn. Educ. Ser. Sydney. 16, 1, 452.

BERTRAND C.E. 1874. Anatomie comparée des tiges et des feuilles chez les Gnétacées et les Conifères. Ann. Sci. nat. Bot., ser. 5, 20: 1-153.

BOUREAU E. 1954. Anatomie végétale. Press. Univ. Fr., Paris (1): 1-330.

BUCHHOLZ J.T. e GRAY N.E. 1948. Ataxonomic revision of Podocarpus I e II. Jour. Arnold Arb. Harvard Uni. 29, 1: 49-76.

BUCHHOLZ J.T. e GRAY N.E. 1948. Idem III e IV. Ibidem 29, 2: 117-151.

BUCHHOLZ J.T. e GRAY N.E. 1951. Idem Vet VI. Ibidem 32, 1: 82-97.

CHAUVEAUD G. 1904. L'appareil sécréteur de l'If (Taxua). Bull. Mus. Hist. nat. Paris. 10: 502-512.

CHEVALIER A. 1951. Plantes remarquables observées en Afrique Equatoriale à l'état vivant au cours d'un voyage en 1950-1951. Rev. Int. Bot. appl. 31: 265-270.

DUARTE A.P. 1973. Tentativa para explicar a ocorrência de duas espécies de Podocarpus no Brasil. Arq. Jard. Bot. Rio de Janeiro, 19: 199-215.

DE FERRE Y. 1952. Les formes de jeunesse des Abiétinées. Ontogénie. Phylogénie. Thése Fac Sci. Toulouse. 1-284.

DE LAUBENFELS D.J. 1969. A revision of the Malesian and Pacific rainforest Conifers.

I. Podocarpaceae, in part. J. Arnold Arbor. 50(2): 274-314.

DE LAUBENFELS, D.J. 1969. Idem. Ibidem. 50(3): 315-369.

DE LAUBENFELS, D.J. 1972. Flore de Madagascar et des Comores. 17. et $18^{\circ}$ Familles: Cycadacées, Podocarpacées. Mus. Nat. Hist. nat., Paris: 1-22.

DE LAUBENFELS, D.J. 1976. The genus Dacrydium in Malaya (Gymnospermae). Blumea. 23: 97-98.

DE LAUBEnfELS, D.J. 1978. The genus Prumnopitys (Podocarpaceae) in Malesia. Blumea. 24: $189-190$.

DE LAUBENFELS, D.F. 1978. The Podocarpus species of Ambon (Podocarpaceae). Blumea. 24: 495-497.

DE LAUBENFELS, D.F. 1980. The endemic species of Podocarpus in New Guinea. Blumea. 26: $139-143$.

DE LAUBENFELS, D.F. 1985. A taxonomic revision of the genus Podocarpus. Blumea. 30: 251-278.

FLORIN R. 1931. Untersuchungen zur Stammergeschichte der Coniferales und Cordaitales. $K$. Svenska Vetenskakad. Handl. 10(1): 1-588.

GAUSSEN H. 1973. Les Gymnospermes actuelles et fossiles. Fasc. 12. Trav. Lab. for. Toulouse, 12(1): 1-143.

GAUSSEN, H. 1974. Idem. Fasc. 13. Ibidem 12(1): 1-208.

GAUSSEN, H. 1976. Idem. Fasc. 14. Ibidem 12(1): 1-266.

GAUSSEN, H. e WOLTZ Ph. 1979. La dérive de Madagascar: L'origine Gondwanienne des Podocarpus africains et malgaches. Cahiers de IIndo-pacifique. Paris, 1(4): 389-404.

GRAY N.E. 1953. A taxonomic revision of Podocarpus. VII, Jour. Arnold. Arb. Harvard Uni. 34(1): 67-76.

GRAY, N.E. 1953. Idem VIII. Ibidem 34(2): 163-175.

GRAY, N.E. 1955. Idem IX. Ibidem 36(2-3): 199-206.

GRAY, N.E. 1956. Idem X. Ibidem 37(2): 160-172.

GRAY, N.E. 1958. Idem XI. Ibidem 39(4): 424-477.

GRAY, N.E. 1960. Idem XII. Ibidem 41(1): 36-39.

GRAY, N.E. 1962. Idem XIII. Ibidem 43(1): 67-79.

GRAFFIN E. 1907. The development of some New Zealand Conifer leaves with regard to transfusion tissue and adaptation to enviroment. Trans. Proceed. New Zealand Inst. 40: 43-72.

GRIFFITH M.M. 1957. Foliar ontogeny in Podocarpus macrophyllus, with special reference to transfusion tissue. Amer. J. Bot. (44): 705-715.

KADAMBARI K. e BECK C.B. 1968. A comparative study of the primary vascular sysiem of Conifers. I. Am. J. Bot. 55(4): 447-457. II. 55(4): 458-463. 
MAHESHWARI p. e VASIL V. 1961. Gnetum. Bot. Monograph. № 1 Counc. Sci. Res.: 1-30. New Delhi.

MAHLERT A. 1885. Beitrage zur Kenntnis der Anatomie der Laubblätter der Coniferen mit besonderer Berücksichtigung des Spaltöffnungs-apparate. Bot. Centlb. 24; 54-59; 85-88; 118-122; $149-153 ; 180-185 ; 214-218 ; 243-249 ; 278-281 ; 310-312$.

ORR M.Y. 1944. The leaf anatomy of Podocarpus. Trans. Bot. Soc. Edimburg. 34(1): 1-54.

QUINN C.J. 1982. Taxonomy of Dacrydium Sol. ex Lamb emend De LAUB. (Podocarpaceae). Aust. J. Bot. 30: 311-320.

ROBYNS W. 1935. Sur les espèces de Podocarpus du Congo Belge et du Ruanda-Urundi. Bull. Inst. Roy. Colon. Belge. 6(1): 226-242.

SAHNI B. 1920. On the structure and affinities of Acmopyle pancheri Pilg. Phil. Trans. Roy. Soc.; London. B, 210: 253-310.

SCHOONRAAD E., 1974. Anatomy of leaves of the genus Podocarpus in South Africa. Phytomorph. 24(1-2): 75-85.

STILES W. 1912. The Podocarpaceae. Ann. of Bot., 26(52): 443-514.

VAN TIEGHEM Ph. 1891. Structure et affinités des stachycarpus, genre nouveau de la famille des conifères. Bull. Soc. Bot. Fr. 38: 162-176.

WOLTZ Ph. e BAILLY Y., 1982. Austrotaxus spicata Compton de Nouvelle-Calédonie: Aspects anatomiques et évolutionde l'appareil conducteur de la plantule. Bull. Soc. Bot. Fr., 126, Lettres bot, (3): 223-230.

WOLTZ Ph., GAJARDO R.E., ROUANE M.L. 1984. A propos du Saxegothaea conpicua Lind. Podocarpine endémique des Andes méridionales et de l'évolution vasculaire de la plantule. Gaussenia (Toulouse) 1: 5-18.

WOLTZ Ph., 1986. Les Podocarpus (s.1.), origines et évolution. Études des plantules; comparaison avec les familles de Conifères de l'hémisphère sud. Thèse doct d'Etat, Univ. Aix-Marseille 3: 1-190. 